\title{
Viscosity and Diffusion of Small Normal and Isomeric Alkanes: An Equilibrium Molecular Dynamics Simulation Study
}

\author{
Choong Do Yoo, Soon-Chul Kim, and Song Hi Lee \\ Department of Chemistry, Kytngsung Lniversity, Busan 608-736, Korea. ${ }^{*}$ E-mail: shleegks.ackr \\ Department of Physics, Andong National Lniversity, Andong 760-749, Korea \\ Received Februarv 28, 2008
}

Key Words : Diffusion. Viscosity , Normal alkanes. Isomeric alkanes. Molecular dỵnamics simulation

Constitutional isomers ${ }^{\mathrm{l}}$ have different physical properties that have the same carbon number but different structures. The difference may not be large, but they are found to have different melting points. boiling points. densities. indexes of refraction, and so forth. For example. a branched chain isoner has a lower boiling point than a straight chain isomer. Thus normal pentane has a boiling point of $36^{\circ} \mathrm{C}$, isopentane with a single branch $28^{\circ} \mathrm{C}$, and neopentane with two branches $9.5^{\circ} \mathrm{C}$. This effect of branching on boiling point is observed within all families of organic compounds. It is reasonable that branching should lower the boiling point: with brancling the molecular shape tends to approach to that of a sphere and as this happens the surface area decreases. as the result of that the intermolecular forces become weaker and are overcome at a lower tentperature.

The branching effect on the dymanic properties of liquid alkanes, such as self-diffusion constant, viscosity, and thermal conductivity, is one of the most interesting phenomena. For liquid butane. the experimentally observed behavior 2 tells us that viscosity increases with branching. For liquid pentane, hexane, and heptane, however, branching decreases the viscosity. for example, 0.289 and $0.273 \mathrm{cp}$ at $273.15 \mathrm{~K}$. and 0.240 and $0.223 \mathrm{cp}$ at $293.15 \mathrm{~K}$ for normal pentane and isopentane. 0.326 and $0.306 \mathrm{cp}$ at $293.15 \mathrm{~K}$ for normal hexane and isolhexane. and 0.409 and $0.384 \mathrm{cp}$ at $293.15 \mathrm{~K}$ for nomal heptane and isoheptane, ${ }^{3}$ respectively. These experimental results, except for liquid butane. indicate that as the molecular shape tends to approach that of a sphere and the surface area tends to decrease with branching, the intermolecular forces becomes weaker and the viscosity of alkane isonters decreases.

In the present note, we report equilibrium molecular dynanics (MD) simulations for the systems of small normal and isomeric alkanes - nonmal butane and isobutane, normal pentane and isopentane. and normal hexane and isolnexane. The printary study goal is to analyze the diffusion and viscosity dynanics of small normal and isomeric alkanes at different temperatures.

\section{Molecular Models and MD Simulation Methods}

For snall normal alkanes, we have chosen 3 systems normal butane $\left(\mathrm{C}_{4} \mathrm{H}_{10}\right)$, normal pentane $\left(\mathrm{C}_{5} \mathrm{H}_{3}\right)$, and normal hexane $\left(\mathrm{C}_{6} \mathrm{H}_{14}\right)$, and the corresponding isomeric alkane systems are isobutane $\left(\mathrm{C}_{4} \mathrm{H}_{10}\right)$. isopentane $\left(\mathrm{C}_{5} \mathrm{H}_{12}\right)$, and isohexane $\left(\mathrm{C}_{6} \mathrm{H}_{14}\right)$. Each simulation was carried out in the NVT ensemble: the number of n-alkane was $N=100$ and the lengths of cubic simulation boxes were obtained from the experimental densities ${ }^{4}$ for given temperatures of 248.273. 293 and $298 \mathrm{~K}$. The usual periodic boundary condition in the $\mathrm{x}-\mathrm{y}-$, and $\mathrm{z}$-directions and the minimum image convention for pair potential were applied. Gaussian isokinetics was used to keep the temperature of the system constant. ${ }^{5}$

We used a united atom (UA) model for n-alkanes. that is, methyl and methylene groups are considered as spherical interaction sites centered at each carbon atom. This model was used in the previous simulation studies. ${ }^{6-10}$ Here. we briefly describe the salient features of the model. The interaction between the sites on different $n$-alkane molecules and between the sites separated by more than three bonds in the same $n$-alkane molecule was described by a Lennard-Jones (LJ) potential. All the sites in a chain have the same LJ size parameter $\sigma_{1} \equiv \sigma_{\mathrm{l}}=3.93 \mathrm{~A}$, and the well depth parameters were $\varepsilon_{\mathrm{l}} \equiv \varepsilon_{\mathrm{u}}=0.94784 \mathrm{~kJ} / \mathrm{mol}$ for interactions between the end sites and $\varepsilon_{\mathrm{l}}=0.39078 \mathrm{~kJ} / \mathrm{mol}$ for interactions between the internal sites. The Lorentz-Berthelot combining rules [ $\varepsilon_{\text {] }}$ $\left.\equiv\left(\varepsilon_{\mathrm{l}} \varepsilon_{\mathrm{j}}\right)^{\mathrm{s} 2}, \sigma_{\mathrm{Jl}} \equiv\left(\sigma_{\mathrm{l}}+\sigma_{1}\right) / 2\right]$ were used for interactions between an end site and an internal site. A cut-off distance of $2.5 \sigma_{i}$ was used for all the LJ interactions.

Initially the bond-stretching was described by a harmonic potential. with an equilibrium bond distance of $1.54 \mathrm{~A}$ and a force constant of $1882.8 \mathrm{~kJ} / \mathrm{mol} / \AA^{2}$. The bond bending interaction was also described by a hamonic potential with an equilibrium angle of $114^{\circ}$ and a force constant of 0.079187 $\mathrm{kJ} / \mathrm{mol} /$ degree $\mathrm{e}^{2}$. The torsional interaction was described by the potential developed by Jorgensen et $a t^{11}$.

$$
U_{\text {torsion }}(\phi)=a_{1 j}+a_{1} \cos \phi+a_{2} \cos ^{2} \phi+a_{3} \cos ^{3} \phi .
$$

where $\phi$ is the dihedral angle. and $a_{1}=8.3973 \mathrm{~kJ} / \mathrm{mol}, \mathrm{a}_{]}=$ $16.7862 \mathrm{~kJ} / \mathrm{mol}$. $\mathrm{a}_{2}=1.1339 \mathrm{~kJ} / \mathrm{mol}$. and $\mathrm{a}_{3}=-26.3174 \mathrm{~kJ} /$ mol. For the time integration of the equations of motion, we adopted Gear's fifth-order predictor-corrector algoritlum ${ }^{13}$ with a time step of 0.5 femto-second for all the systems Later the bond-stretching was switched to a constraint force which keeps intramolecular nearest neighbors at a fixed distance. The advantage for this change is to increase the time step as 5 femto-seconds with the use of RATTLE algorithm. ${ }^{13}$ After a total of $1,000.000$ time steps (5 nano- 
seconds) for equilibration. the equilibrium properties were then averaged over 5 blocks of 200.000 time steps (1 nanoseconds). The configurations of all the molecules for further analyses were stored every 10 time steps $(0.05$ pico second) which is small enough for the tick of any time autocorrelation functions.

Self-diffusion constant (D) can be obtained through two routes: the Green-Kubo formula from velocity auto-correlation functions (VAC):

$$
D=\frac{1}{3} \int_{0}^{c_{0}}\left\langle\mathbf{v}_{\mathrm{i}}(t) \cdot \mathbf{v}_{\mathrm{j}}(0)\right\rangle d t
$$

and the Einstein formula from mean square displacements (MSD):

$$
D_{s}=\frac{1}{6} \lim _{t \rightarrow \infty} \frac{d<|\mathbf{r}(t)-\mathbf{r}(0)|^{2}}{d t}
$$

Shear viscosity is calculated by a modified Green-Kubo formula for a better statistical accuracy ${ }^{14,15}$ :

$$
\eta=\frac{V}{k T} \int_{i ! 1}^{\infty} d t \sum_{j}\left\langle P_{j \alpha \beta}(0) P_{j \alpha \beta}(t)\right\rangle .
$$

where $P_{z \alpha \beta}$ is the $\alpha \beta$ component of the molecular stress tensor. $\mathbf{P}_{i}$, of particle $i$ by translational motion:

$$
P_{j \alpha \beta}(t)=\frac{1}{V}\left[m v_{r \alpha}(t) v_{i j}(t)+\sum_{j \neq j} r_{i j \alpha}(t) f_{i j \beta}(t)\right] .
$$

where $\alpha \beta=\mathrm{xy} . \mathrm{xz}, \mathrm{yx}, \mathrm{yz} . \mathrm{zx}$, or $\mathrm{zy}$.

\section{Results and Discussion}

We compare the results of self-diffusion constants of normal alkanes and isomeric alkanes. In Figure I the log-log plot of self-diffusion constant (D) versus molecular mass (M) is shown for several temperatures. Calculated selfdiffusion constants of liquid isobutane are larger than those of liquid nonnal butane over four different temperatures while the opposite is observed for liquid pentane and

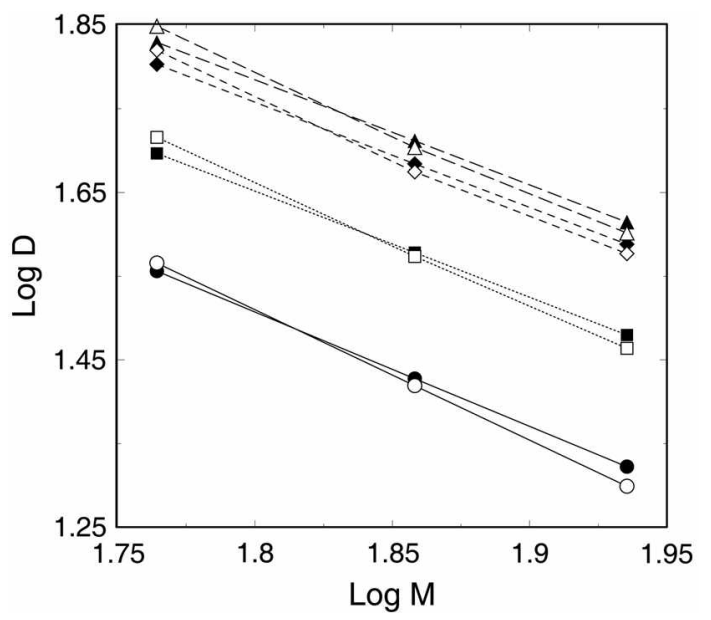

Figure 1. A log-log plot of D $\left(10^{-6} \mathrm{~cm}^{2} / \mathrm{sec}\right)$ vs. M $(\mathrm{g} / \mathrm{mol})$. From top, $\mathrm{T}=298(\boldsymbol{\Delta}), 293(\bullet), 273(\boldsymbol{\square})$, and $248 \mathrm{~K}(\boldsymbol{\bullet})$, respectively. Black: normal alkanes and white: isomeric alkanes. hexane. The crosses of the slope lines in Figure 1 represent this. The slopes are almost linear for given temperatures, which indicates that the behavior of $\mathrm{D}$ w. M is well described by $\mathrm{D} \sim \mathrm{M}^{-\alpha}$. The obtained exponents are between 1.25 and 1.36 for liquid normal alkanes and between 1.45 and 1.56 for liquid isomeric alkanes. At the molecular weight of the Rouse regime (the polymer chain dynamics of unentangled chains is commonly described by the Rouse), D of nommal alkanes also show power law behaviors. For example, D of nomal alkanes for nomal octane to polyethylene of the molecular weight of several thousands was reported that the exponents $\mathrm{a}$ is in the range of 1.75-2.72 depending on temperature. ${ }^{16-18}$ Our previous MD simulation studies $^{19}$ for normal $\mathrm{C}_{12}=\mathrm{C}_{44}$ at $\mathrm{T}=273-473 \mathrm{~K}$ are another examples. The obtained exponents are between 1.6 and 2.4. Apparently the exponent in liquid alkanes decreases with temperature.

Viscosities of liquid normal and isomeric alkanes obtained from the modified Green-Kubo relation. Eq. (3), underestimate the experimental values: comparing in the unit of $\mathrm{cp}$, $0.289 / 0.193$ at $273.15 \mathrm{~K}$ and $0.240 / 0.147$ at $293.15 \mathrm{~K}$ for nommal pentane. $0.273 / 0.133$ at $273.15 \mathrm{~K}$ and $0.223 / 0.106$ at $293.15 \mathrm{~K}$ for isomeric pentane. $0.40 \mathrm{l} / 0.297$ at $273.15 \mathrm{~K}$ and $0.326 / 0.226$ at $293.15 \mathrm{~K}$ for normal hexane. and $0.376 / 0.266$ at $273.15 \mathrm{~K}$ and $0.306 / 0.182$ at $293.15 \mathrm{~K}$ for liquid isomeric hexane, respectively. The difference is severe in isomeric alkanes. Figure 2 shows the $\log -\log$ plot of viscosity $(\eta)$ versus molecular mass (M). Calculated viscosities of liquid isomeric alkanes are always smaller than those of liquid normal alkanes over four different temperatures. The slopes are almost linear for given temperatures, which indicates that the behavior of $\eta w s . \mathrm{M}$ is well described by $\eta \sim \mathrm{M}^{\beta}$. The obtained exponents are between 2.32 and 2.47 for liquid normal alkanes and between 1.77 and 1.98 for liquid isomeric alkanes. The experimental results for normal alkanes and linear polyethylene ${ }^{17}$ show that $\eta$ is also well described by the power law: $\eta \sim \mathrm{M}^{1.8}$ at low molecular weight $(\mathrm{M}<5$ $\mathrm{kg} / \mathrm{mol})$ and $\eta \sim \mathrm{M}^{3.6}$ at high molecular weight $(\mathrm{M}>5 \mathrm{~kg} /$

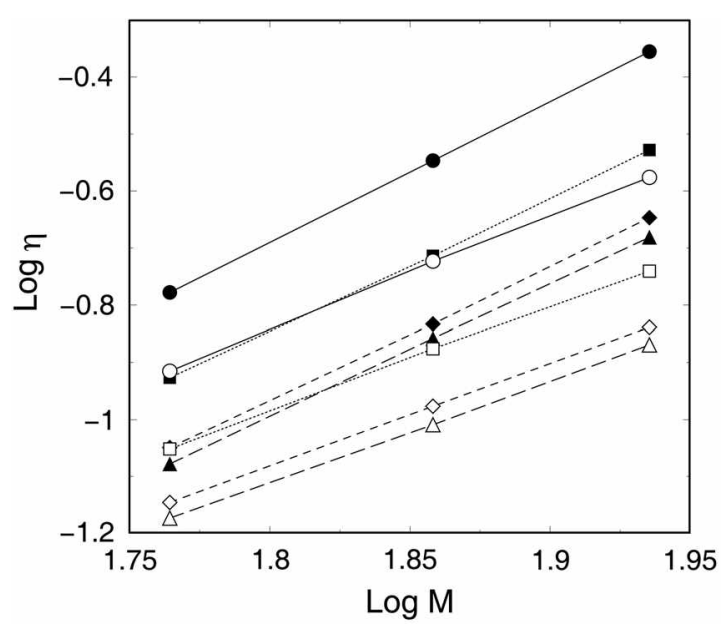

Figure 2. A log-log plot of $\eta$ vs. $\mathrm{M}(\mathrm{g} / \mathrm{mol})$. From top, $\mathrm{T}=248$ (๑), $273(\boldsymbol{\square}), 293(\bullet)$, and $293 \mathrm{~K}(\boldsymbol{\Delta})$, respectively. Black: nomal alkanes and white: isomeric alkanes. 
mol) at $448 \mathrm{~K}$. Our previous MD simulation studies ${ }^{19}$ for nonnal $\mathrm{C}_{12}=\mathrm{C}_{+4}$ at $\mathrm{T}=273-473 \mathrm{~K}$ gives the obtained exponents between 2.0 and 3.7. Assumably the exponent in liquid nonmal alkanes decreases with temperature in the same direction to the exponent in the log-log plot of selfdiffusion constant (D) versus molecular mass (M) discussed above.

Experimental measurements show that the viscosity of liquid isomeric butane is higher than that of liquid nonmal butane at $298 \mathrm{~K}(0.166 / 0.162 \mathrm{cp})$ and also for gas state $(76.14 / 75.43 \mathrm{mp}){ }^{4}{ }^{4}$ However, branching decreases the viscosity for liquid pentane. hexane, and heptane as discussed above. The simulation results underestimate the experimental values for both liquid isomeric and normal butanes $(0.0632 / 0.0836 \mathrm{cp})$, and show that branching decreases the viscosity in contradiction to the experimental trend. A similar result for the viscosity of liquid butanes was reported in the non-equilibrium MD simulation using UA model for liquid butanes. ${ }^{\text {*I }}$

Usually the behavior of self-diffusion constant (D) in long chains of alkanes is the opposite to that of viscosity $(\eta)$. For liquid butane, calculated self-diffusion constants (D) of nornal alkanes are smaller than those of isomeric alkanes and the opposite is observed for calculated viscosities $(\eta)$. However, exceptionally both calculated self-diffusion constants (D) and viscosities ( $\eta$ ) of liquid normal pentane and hexane are larger than those of liquid isomeric alkanes. From Figures 1 and 2, the increase in the exponent of the $\log$-log plot of self-diffusion constant (D) versus molecular mass (M) from normal alkanes to isomeric alkanes ( $1.3 \rightarrow$ 1.5. averagely) agrees with the decrease in the exponent of the log-log plot of viscosity $(\eta)$ versus molecular mass (M) $(2.4 \rightarrow 1.9$, averagely) and the product of two exponents are almost constant (3.1 vs. 2.9).

The temperature dependence of the calculated diffusion constants of liquid $n$-alkanes over the whole temperatures considered is suitably described by an Arrhenius plot, $\mathrm{D}=$ $D_{0} \exp \left(-E_{D} / R T\right)$, as shown in Figure 3 , where $D_{0}$ is the pre-

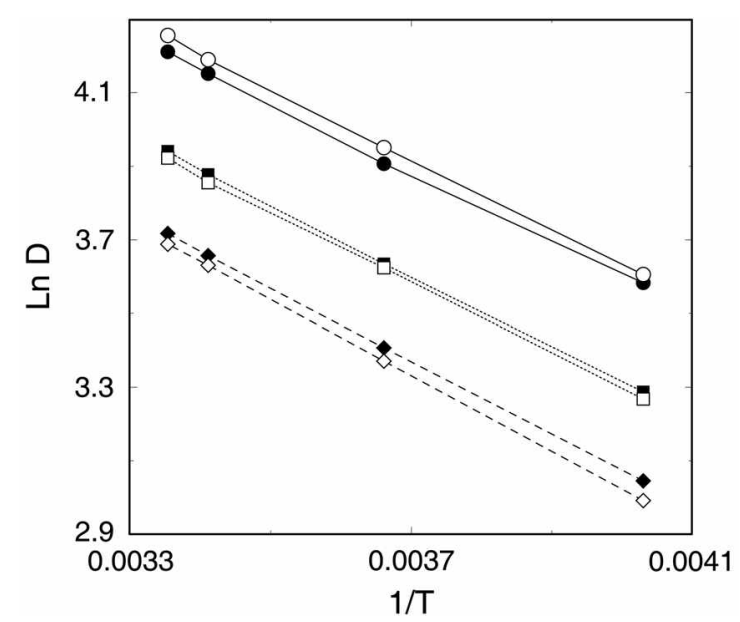

Figure 3. Arthenius plot of $\mathrm{D}\left(10^{-5} \mathrm{~cm}^{2} / \mathrm{sec}\right)$ ws. 1/T. From top, $\mathrm{C}_{4}$ $\left(-C_{5}(\boldsymbol{\square})\right.$, and $C_{6}(\bullet)$, respectively. Black: nomal alkanes and white: isomeric alkanes.

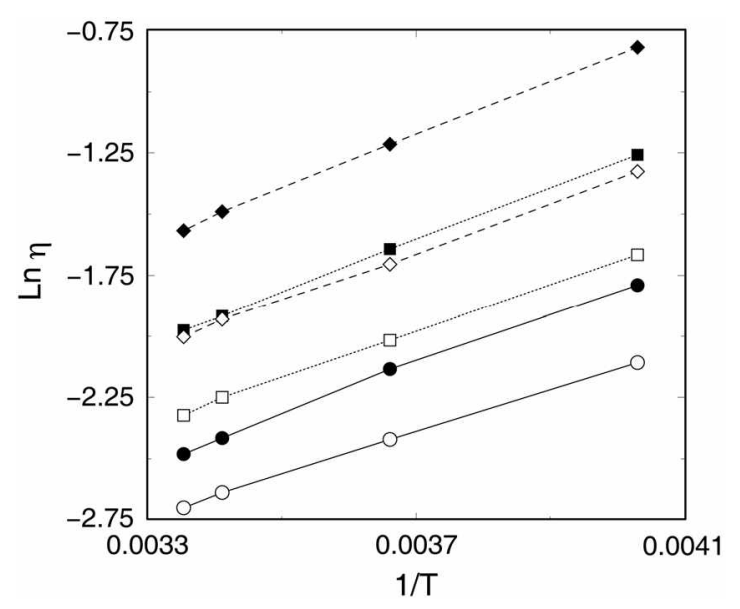

Figure 4 . Arrhenius plot of $\eta$ (cp) $w$. $1 / \mathrm{T}$. From top, $\mathrm{C}_{\mathrm{n}}(\bullet), \mathrm{C}_{s}$ (ם), and $C_{+}(\mathbf{O})$, respectively. Black: nonmal alkanes and white: isomeric alkanes.

exponential factor. RT has the usual meaning. and $E_{\square}$ is the activation energy of nomal alkane diffusion. The value of the activation energy is a direct measure of how fast the selfdiffusion changes with temperature. The activation energies obtained from the slope of the least square fit are 1.84, 1.91, and $1.97 \mathrm{kcal} / \mathrm{mol}$ for liquid normal alkanes and $1.90,1.95$. and $2.05 \mathrm{kcal} / \mathrm{mol}$ for liquid isomeric alkanes. respectively. The activation energies of nomal alkane diffusion are smaller than those of isomeric alkane diffusion. Our previous MD simulation studies ${ }^{19}$ for nonmal $\mathrm{C}_{12}-\mathrm{C}_{44}$ at $\mathrm{T}=273.473 \mathrm{~K}$ gives the activation energies of $2.83 .3 .52,3.91$. and 4.06 $\mathrm{kcal} / \mathrm{mol}$ for $\mathrm{C}_{12}, \mathrm{C}_{2 !}, \mathrm{C}_{32}$, and $\mathrm{C}_{44}$, respectively. $E_{1}$, is small for small alkanes.

We also show the temperature dependence of the calculated viscosities of liquid $n$-alkanes over the temperatures which is also suitably described by an Arrhenius plot, $\eta=$ $\eta_{\circ} \exp \left(\mathrm{E}_{\eta} / \mathrm{RT}\right)$. as shown in Figure 4: where $\eta_{0}$ is the preexponential factor and $E_{\eta}$ is the activation energy of $n$ alkane viscosity. The activation energies obtained from the slope of the least square fit are 2.03 .2 .11 . and $2.18 \mathrm{kcal} / \mathrm{mol}$ for liquid nonmal alkanes and $1.73,1.91$, and $1.97 \mathrm{kcal} / \mathrm{mol}$ for liquid isomeric alkanes. respectively: The activation energies of normal alkane viscosity are larger than those of isomeric alkane viscosity. which is opposite to that of diffusion. Our previous MD simulation studies ${ }^{19}$ for normal $\mathrm{C}_{12}-\mathrm{C}_{44}$ at $\mathrm{T}=273-473 \mathrm{~K}$ gives the activation energies of 2.33. 3.29. 4.63, and $5.46 \mathrm{kcal} / \mathrm{mol}$ for $\mathrm{C}_{13} . \mathrm{C}_{331}, \mathrm{C}_{33}$. and $\mathrm{C}_{44}$, respectively. $E_{\eta}$ is also small for small alkanes. It was experimentally reported for $n$-alkanes and linear polyethylene ${ }^{17}$ that the activation energy increases with chain length and at the lighest molecular weight tested $(M \sim 4.4 \mathrm{~kg} / \mathrm{mol})$ the activation energy reaches $6.6 \mathrm{kcal} / \mathrm{mol}$. which is similar to the average value found for NBS (National Bureau Standard) $1482-4(6.7 \mathrm{kcal} / \mathrm{mol})$ and the values reported by others $^{21.22}$ for high molecular weight linear polyetlylene ( $6.1-6.9 \mathrm{kcal} / \mathrm{mol})$. As chain length $n$ increases the increment of $E_{\eta}$ decreases, and it is expected to approach an asymptotic value as $n$ increases to the higher values. 
In summary, self-diffusion constants (D) of liquid isobutane obtained in this study are larger than those of liquid normal butane over four different temperatures while the opposite is observed for liquid pentane and hexane. Viscosities $(\eta)$ of liquid normal alkanes are larger than those of liquid isomeric alkanes. which agrees with the experimental result except liquid butane. The usual opposition in the trends of self-diffusion constant and viscosity is not applied to small liquid alkanes.

Acknowledgments. This work was supported by Grant No. R01-2003-000-10327-0 from the Basic Research Program of the Korea Science and Engineering Foundation Grant. This research is a partial fulfillment of the requirements for the degree of Ph. D. of Science for CDY at Department of Chemistry. Graduate School. Kyungsung University.

\section{References}

1. Graham Solomon. T. W. Organic Chemistry 4th ed: John Wiley and Sons: New York. 1988.

2. Diller. D. E.: van Poolen. L. J. Int. J. Thermophnsics 1985. 6. 43.

3. Weast. R. C.: Astle. M. J. CRC Hondbook of Chemisty and Plvosics. 63rd ed.: CRC press: Boca Ranton. 1982-1983.

4. Gallant R. W. Phnsical Properties of Hydrocarbons: Gulf Pub: Houston, 1968

5. Evans, D. J. Hooter, W. G. Failor B. H.: Moran B.: Ladd. A. I.
C. Phys. Rev 1983. A28. 1016. (b) Simmons. A. T. D.: Cummings. P. T. Chent. Phus Lett. 1986. 129.92.

6. Siepmant1. J. I.: Karaborni. S.: Snit. B. Natme (London) 1993. 365.330 .

7. Smit. B.; Karaborni. S.; Siepmann, J. I. J. Chem. Phys. $1995,102$. 2126.

8. Mundy. C. J.: Siepmann. J. I.: Klein. M. L. J. Chent. Phys. 1995. 102.3376

9. Cui. S. T.: Cummings. P. T.: Cochran. H. D. J. Chent Phns 1996. 104. 255.

10. Cui, S. T.; Gupta, S. A.: Cummings, P. T.; Cochran, H. D. $d$. Chem. Phus. 1996, 105. 1214.

11. Jorgensent. W. L.: Madura. J. D.: Swenson. C. T. J. Am. Chent. Soc. 1984. 106.6638.

12. Gear. C. W. Numerical Initial Value Problents in Ordinary Differential Equation; Prentice-Hall: Englewood Cliffs. 1971.

13. Andersen, H. J. Comput. Phys. 1984, 52. 24.

14. Lee. S. H. Bull. Kor: Chem. So. 2007. 28, 1371.

15. Min. S. H.: Son1. C. M.: Lee. S. H. Bull. Kot Chent Soc. 2007.28. 1689.

16. Fleisher. G. Pohnt. Bull. (Berlin) 1983. 9. 152.

17. Pearson, D. S.; Ver Strate, G.: von Meerwall, E; Schilling, F. C. Macromolecules 1987. 20,1133.

18. Von Meerwall. E.; Beckman. S.; Jang. J; Mattice. W. L. J. Chem. Pho 1998. J08. 4299.

19. Lee. S. H.: Chang. T. Bull. Kon Chem. Soc. 2003. 24. 1590.

20. Lee. S. H.: Cummings. P. T. Mol. Sint 1996. 16. 229.

21. Mendelson, R. A.;. Bowles. W. A.: Finer. F. L. J. Polvm. Sci. Part A-2. 1970, 8, 105

22. Raju. V. R.; Smith, G. G.: Marin. G.: Knox, J. R.: Graessley, W. W. J. Polm. Sci. Pohyn. Phus Ed 1979.17.1183. 